\title{
Read My Voice: Expressing Silence and Sound in Text-messages
}

\author{
AGNIESZKA KNAS, Queen Mary, University of London
}

\begin{abstract}
Texting as a modality of computer-mediated communication (CMC) has attracted the attention of researchers as a sociological and linguistic phenomenon. They have focused on usage patterns and peculiarities of SMS-language, while other, more complex forms of $\mathrm{CMC}$ have been discussed as a field for creating virtual communities and co-constructing social realities. In this paper, I establish that texters co-opt technology to record audible features in writing, and propose that 'text tools' employed to replace voice features can be divided into three categories: silences, fillers, and phoneticons. Based on samples of English and Polish texts, I establish that silence and voice features are present in texting and play an important role in increasing the perception of physical proximity of the participants. This paper advances current knowledge about text-messages and contributes to questions about the ways non-verbal features are marked and the illusion of conversational reality created in this important, but often overlooked, medium.
\end{abstract}

\section{KEYWORDS}

Text-messages; silence; sound; fillers; phoneticons.

\section{Introduction}

With the development of new modes of computer-mediated communication (CMC), the range of communicative possibilities has vastly expanded. New modes allow not only for the transfer of text, but also other forms of data, e.g., images. Even mobile phone users have gained the possibility to transfer files (e.g., in MMS-messages or via Bluetooth) and take part in synchronous communicative exchanges (e.g., through the BlackBerry Messenger). Despite these technological advances, texting, one of the simplest forms of mobile phone communication, has maintained its well-established position.

Even if one takes into account the ubiquity of $\mathrm{CMC}$, texting has received relatively little scholarly interest. Texting attracted the attention of linguists and sociologists, especially in its early days, who analysed communication by means of this mediated modality, concentrating mainly on the unique language employed in text-messages, their main functions and popularity (Thurlow, 2003; Hård af Segerstad, 2002; Ling, 2004). Research questions of online communication analysis, such as those of identity construction, creating communities across time and space, and conversation analysis have not been taken into account in the study of texting. 
This paper shows that technologically mediated communication, including texting, has fostered the development of new textual ways of rendering voice qualities in writing. It also shows that texters devote their time and attention to representing sound qualities and silence in their text-messages: features that are metalinguistically redundant in this verbally minimalist form of communication. I establish that 'text tools' employed to create an illusion of face-to-face exchanges can be divided into three categories based on their form and function: silences, fillers, and phoneticons. These categories will be discussed in greater detail later in this paper. At this stage I will only provide a general definition and criteria for classification:

- silences are expressed in writing by means of punctuation (mainly by means of ellipses '...') and verbal descriptions. In certain cases, silence is not explicitly expressed in any form, but its occurrence can be inferred based on context or content of the message.

- fillers replace redundant pauses and mark message-processing, uncertainty, or unwillingness to give up the floor to another participant. They are represented in writing by means of tokens, such as 'hmm', which do not carry propositional meaning, but express the sender's attitude to the message or the ongoing conversational exchange.

- phoneticons are graphemic representations of voice features in writing, including length of sounds, volume, and atypical pronunciation. They are most often represented by capitalized or repeated letters, e.g., 'WHAAAT?'

Comparing two samples of text-messages, in English and Polish, provides an overview of the global character of the described phenomena. It will show the differences and similarities between the two groups, leading to conclusions about issues to consider in the process of developing mobile phone applications.

This study also contributes to the consideration of questions related to the study of mobile phone communication: How would mobile interactions change if the display of silence and sound were to be automatized? Will the distinction between texting and 'more visual' forms of mobile phone communication blur or will the need for textonly communication prevail?

\section{The use of silence and sound in conversation}

The 'real world', as opposed to the mediated one, is full of sounds: human voices, mediated voices (e.g., music player, television), surrounding environment (e.g., cars driving by, coins falling on the floor, keyboard tapping). Face-to-face communication requires sound (or gestures in the case of sign language, which I will not address here) and sound carries meaning. Even without understanding words, we are able to understand the overall tone of communication, making inferences from the tone of voice, its pitch, the pace of uttering words, and accompanying sounds, such as smacking one's lips or hissing. Complete silence, understood as the absence of sound, is rare. Mediated environments are the opposite: apart from the sounds that accompany creating the message and possible vocal reactions to received messages, 
text displayed on the computer screen in text-only modes of CMC does not carry any sound. Through written verbalizations, it carries meanings and attitudes and can convey the sender's stance towards the message or the ongoing situation. Nevertheless, paralinguistic communication in a silent mediated context is still possible. The following subsections provide an account of earlier research devoted to silence and sound in communication.

\subsection{Silence}

It is generally accepted that silence is an indispensable part of linguistic communication (Rokoszowa, 1999; Handke, 2002). There are various points of view as to how silence should be defined and whether, and in what form, it is at all possible (Miller, 1993). The term has proved to be relatively difficult to define throughout the years. Most definitions concentrate on the acoustic features of silence, namely on the lack of physical sound produced. They are usually based on negative constructions, including words such as 'lack', 'no', or 'absence', and include reference to 'speaking', 'writing', and 'the use of language' (Rokoszowa, 1999, p. 225). The New Oxford Dictionary of English defines silence as 'complete absence of sound' (1998, p. 1733). Miller, commenting on a definition according to which silence is the 'state or condition when nothing is audible; absence of all sound or noise; complete quietness or stillness; noiselessness' (1993, p. 10), states that the term silence 'refers to communication, or rather, non-communication, irrelevance, a non-message' (1993, p. 112).

The study of silence is not extensive, as silence was for a long time neglected as a part of conversation worth analysing (but see Tannen, 1985; Jaworski, 1993). Studies of silence concentrate on oral face-to-face conversations, as well as communication that takes place in various environments, e.g., lectures, speeches, interviews, among others.

An important point to make is that silence is traditionally accepted as a feature of spoken communication and thus its written form has rarely been discussed. One of the very few examples is the analysis of pauses between a letter and a response treated as silence in written communication (Schmitz, 1994). Long pauses often result from the need to construct a message, in this case a letter, so that it carries the intended meaning in the recipient's different situational and temporal context. This understanding can also be relevant to the study of text-messages, as they can be functionally compared to letters.

However, text-messages are often treated by participants as a mode of synchronous communication in the manner of oral face-to-face interaction in that they often involve a series of messages constituting a communicative exchange. It will be shown later in this paper that text-messages, even though formally a form of asynchronous communication, resemble synchronous exchanges in their structure and content. For example, texters signal uncertainty and difficulty in constructing a message through fillers and self-corrections. Therefore, silence in writing should be seen as occurring not only between messages, but also within. In the latter case, it can be encoded by means of punctuation and empty spaces. In this paper, reference will be made to the 
categories of 'fore-silences' and 'after-silences' (see Dauenhauer, 1973) to represent the part of a message that a particular instance of silence can be related to.

As far as the function of silence is concerned, a variety of propositions appear in the current literature on the subject. Silence was initially considered to be a sign of unfriendliness and bad character and its suspension was treated as 'the first act to establish links of fellowship' (Malinowski, 1923, p. 314). This point of view is confirmed by Laver, who refers to 'the potential hostility of silence' (1981, p. 301). Depending on the context in which a particular instance of silence occurs and on its length, silence has the following functions: creating intimacy, organizing an utterance, signalling hesitation or lack of knowledge, and following local norms (Handke, 2002). Thus, refraining from speaking should not be interpreted directly as unwillingness to speak or to reveal information. As Rokoszowa (1999) claims, even in non-delivering a verbal message, remaining silent, or providing only partial information (Handke, 2002) one conveys meaning. Silence, understood as 'absence of something that we expect to hear on a given occasion, when we assume it is "there" but remains unsaid" (Jaworski, 2000, p. 113), is a way of conveying meaning that the recipient (or hearer) is expected to understand from the context. This form of silence finds its equivalent in text-messages as well.

Silence is used to organize and define relations between the participants of the interaction; it helps to express meanings which cannot be expressed by means of words (Żydek-Bednarczuk, 1994; Rokoszowa, 1999); and sometimes serves as a politeness strategy, e.g., 'formulaic silences', like 'small talk', are used as a routine response to face-threatening acts (Jaworski, 2000). It needs to be emphasized that the distribution and functions of silence are culturally dependent (Sajavaara \& Lehtonen, 1997; Jaworski, 2000). In some cultures, silence can express agreement and, in others, lack of consent. It can serve to build the feeling of intimacy and appear as a response to emotional intensity (Miller, 1993). In numerous cases, silence co-occurs with nonverbal communication and fillers, which help disambiguate its meaning and facilitate mutual understanding between interactants.

\subsection{Sound}

Paralinguistic and communicatively meaningful sounds in conversation can be seen from various perspectives: they can be analysed as voice quality features while uttering words (prosodic features), or as sounds independent of a message content, but integral to communication. Prosodic features are investigated in linguistic research (usually based on voice recordings of verbal exchanges) in analysing pronunciation characteristic of given dialects and language varieties, in variationist analyses of speech communities, etc. The meaning and function of sounds independent from verbalized forms present in the interactive space have rarely been discussed in communication research (but see the analysis of the visual representation of sounds in comic books in Kurc, 2003). In both cases, that of silence and that of sound, non$\mathrm{CMC}$ research concentrates mainly on spoken interactions. In CMC research, certain elements, such as backchannel expressions, that enter into modes of written communication through mediated contexts of spoken-like interactions in chats and MUDs are investigated. 
Textual representation of auditory information, such as prosody, laughter, and other non-language sounds, has been only briefly discussed in CMC literature. Analyses focused mainly on the unconventional orthography related to such instances. Other research in which interest in the reproduction of sound was transferred from face-toface to $\mathrm{CMC}$ has occurred in two primary domains: Own Communication Management (OCM) markers (Allwood, 2000) and laughter (del-Teso-Craviotto, 2006).

The function of OCM markers is 'to enable a communicator to choose and change their message' (Allwood, 2000, p. 17). Their importance in conversations has been noted in conversation analysis, where they have been discussed as utterancestructuring elements facilitating conversation (marking openings and closings of discourse units or transitions between them), as modality or attitudinal indicators, as markers of speaker-hearer intentions and relationships, and as instructions on how given utterances are to be processed. They are often labelled as fillers, in reference to filled pauses in which they occur, and treated as a type of discourse marker or as a type of nonverbal communication (cf., Poyatos, 1992) that does not add to the propositional meaning of the utterance. They are hesitation sounds that speakers employ to indicate uncertainty, attention or recognition, express agreement (Tannen, 2002), or maintain control of a conversation while thinking of what to say next (cf., Żydek-Bednarczuk, 1994; Maschler, 1998). They occur predominantly in an utterance-initial position and bear the function of modality or attitudinal indicators.

Among the OCM features found in her sample of Swedish text-messages, Hård af Segerstad (2005) mentions 'eh', 'öh', and 'hmm'. She points to the fact that these features, just like dialectal words, interjections, and prosody, are not usually spelt out in writing (Hård af Segerstad, 2002). They are usually associated with informality. Sound qualities analysed in both spoken interaction and written text are voice qualities like the length of sound, atypical pronunciation, and fillers, including filled pauses, interjections, response cries (Goffman, 1978), and backchannel expressions (Yngve, 1970). Their functions can vary, depending on the immediate context of their occurrence, as well as on the whole situational context. Due to their character, fillers are prone to variations in the final sound length. The differences can be treated as cultural or idiosyncratic, as well as resulting from the degrees of emotions expressed.

Laughter has also been analysed not for its acoustic features, but as an example of language use and communication online. It has been described as by far the most common face-saving strategy in dating chatrooms (del-Teso-Craviotto, 2006). Laughter is expressed through onomatopoeia ('ja', 'he'), emoticons (graphic representations of facial expressions, such as :-) or x-D), or acronyms (e.g. 'lol' for 'laughing out loud', or 'lmao' for 'laughing my ass off'). Some of the conventions used for reproducing voice features, such as onomatopoeic words, capital letters to express a higher volume, or repetition of letters to express longer sounds, are found in other written media (e.g., movie scripts and comic books), while others, such as acronyms, are mostly found in CMC. To enhance the feeling of playfulness and to create the illusion of intimacy in dating chats, users reproduce a very casual pronunciation in typed messages. Del-Teso-Craviotto (2004) shows how participants in Spanish dating chat rooms exploit written language for expressive purposes and reproduce paralinguistic features, such as volume, the length of sounds, laughter, and pronunciation, associated with familiarity and with being funny or silly using 
colloquial phonetic processes, e.g., phonetic features of the Andalusian Spanish dialect and childish pronunciation. Such strategies are seen as demonstrating the users' ability to adapt the computer medium to their expressive needs (Herring, 2001).

Even though there is some discussion of prosodic features in $\mathrm{CMC}$, it concentrates mainly on interactions in chat rooms or other Internet-based communicative modes. There is virtually no mention of prosodic features in communication by means of textmessages.

\section{Silence and sound in text-messages}

Text-messages can be described as a text-only, asynchronous modality of technologically mediated communication. They were meant to facilitate communication through concise textual-verbal messages. Compared to the new possibilities that mediated communication offers, texting can be seen as rather basic. Whereas personalized sounds and images can be attached to MMS-messages, the only way texting extends above textual communication is through preformatted emoticons in the form of small images that can be inserted into the message, a feature offered by only certain handsets (Hård af Segerstad, 2005). Additionally, few types of handsets have a set of animated images available for texters to insert. These usually depict actions, such as kissing, giving flowers, or crying.

Although texters may rarely spend time editing their messages before sending them, asynchronicity of texting allows for careful consideration of the content and form of a message. Therefore, it seems that repair or lack-of-words markers, which are commonly and, in most cases, unconsciously employed in face-to-face interactions, would only occur in text-messages if intended by the sender. Similarly, atypical spelling, mirroring voice features and characteristic pronunciation, as well as markers of silence, can be treated as meaningful and conscious when represented in a textmessage.

Aural cues are believed to be 'filtered-out' (Culnan \& Markus, 1987; Herring, 2001) from computer-mediated communication. As mentioned above, there has been little interest in the voice features in CMC and there have been virtually no studies of silence and sound in text-messages, a modality overlooked in CMC studies partly due to its minimalist character. However, I will show that such a physically constrained modality of persistent communication as the text-message has been co-opted by its users to transmit not only propositional meanings, but sounds and silence normally accompanying face-to-face communication using 'text-tools', such as silences, fillers, and phoneticons.

The present study is based on a sample of 612 texts collected from 54 volunteers in London and 750 texts collected from 62 volunteers in Warsaw (male/female in equal proportion). The respondents were aged 20-29 and they were communicating in an informal friend-friend dyad. Respondents were asked to forward a minimum of ten text-messages held in their Sent folder directly to the researcher's phone or copy them carefully and send them by e-mail. As part of the analysis, the researcher contacted the senders and discussed some of the material. 
In order to protect anonymity and confidentiality of informants, all identifying information was removed and replaced with the name of a category to which a given word belonged in square brackets, e.g., 'London' was replaced by '[city]'. Due to the nature of the analysis, I have not adjusted, corrected, or in any other way changed the original spelling found in the texts. Instances of silence and sound referred to in the paper (apart from silence marked as large pauses) are boldface. All Polish examples quoted in this paper have been given in the original form as well as translated into English. Translation appears in square brackets.

\subsection{Silences}

Despite the text-based character of the medium, silence markers are present in communication by text-messages in both Polish and English samples. Silence is most often depicted by means of punctuation - ellipses ('...'). Other ways of representing silence in texts are through the use of dashes ('- '), empty spaces within a message, and verbal representations. In most cases, it is possible to distinguish between two kinds of silences, referring to messages (or their parts) preceding and following them: 'fore-silences' and 'after-silences' respectively. Such judgement can be based on the content of a message, its context, and the appearance of spaces after or before the representation of silence. However, it is important to note that these judgements cannot be fully relied on due to the character of communication and the scarcity of available contextual information. Again, due to the lack of contextual information, classification of the type of silence in text-messages can sometimes be difficult, but there are examples where the character of silence markers is clear and its meaning can be concluded from the content of the message. Even though silence occurs in both Polish and English samples, it is much more popular among Polish texters, who also seem to be more innovative in displaying it than English senders.

In this paper, silence, understood as a pause between one message and another (see Schmitz, 1994), is disregarded, as it is not relevant to the subject of the analysis. At this stage, it is also impossible to analyse due to the lack of necessary data. The analysis of silence in text-messages will cover instances where silence within a message is represented in writing by means of punctuation, unexpectedly large spaces between words, verbal descriptions, as well as instances where some content of a message that is expected to occur is omitted or barely signalled through abbreviations or incomplete words.

Silence can perform a number of functions in communication by means of textmessages. Below, I explain the ways of signalling silence in texts, as well as its functions in English and Polish text-messages. Wherever possible, I include examples from both samples. In certain cases, however, examples of a particular usage can only be found in one of the samples.

One of the main functions of silence in communication is to signal that time was needed to construct a message. Sometimes this usage takes the form of marking the sender's loss for words. In example (1), the English sender marks silence visually by leaving large gaps between the three parts of the message (probably originally sent as a message in three separate lines but received as in example (1)). Due to interpretational difficulties arising in the case of example (1), the researcher has 
directly contacted the recipient of the message in question, who confirmed that the message had contained unexpectedly large gaps between words and that it had been correctly coded. The interpretation of the unusual spacing pattern as expression of loss for words has also been confirmed by the recipient. Example (2), on the other hand, includes silence markers in the form of ellipses ('...').

(1) Guys, thank you! Ill be in touch!

(2) Ehh...jak pech to pech! Przykro mi strasznie! I jak to mowia...umiesz liczyc, licz na siebie...znowu sie sprawdza...

[Ehh...bad luck! I'm really sorry! And as they say...you know how to count, count on yourself...comes true again...]

The number of silences in one text-message can be seen as an indication that the content of the message is not easy for the sender to express; that is why s/he allows her/himself a lot of time to think and, at the same time, lets the recipient know that the message requires his/her emotional involvement. In both cases, silence is used to express loss for words on the part of the sender. In the English message (1), it is the loss for words due to gratitude, whereas, in the second message, due to sadness. In difficult situations, silence may bring better results than an attempt to comfort another person, which texters seem to realize and are willing to implement in their messages. In such situations, silence can be treated as an example of a politeness strategy on the part of the speaker (sender), who does not want to impose him/herself on the hearer (recipient), especially in the light of the apparent difficult situation.

This leads to another usage of silence, namely silence performing the function of intimacy building. Intimacy can be understood both as creating mental links between communicators and as mutual understanding without words. In some cases, a part of a word or expression is revealed and the remaining part is left for the reader to interpret. Such situations are common in the case of fixed phrases and popular sayings. This can also replace uncomfortable words or information, as in:

(3) Aha! Masz ojca z daleko posunieta skl..... :) Jeszcze raz dzieki, Coreczko!!! [Aha! You have a father suffering from advanced scl..... :) Thank you once again, Daughter!!!]

This usage was only found in the Polish sample. Any instances of shortened words in the English sample can be explained by the need to save space or effort (see also Hård af Segerstad, 2002). In the above example, the after-silence, clearly referring to the preceding partially disclosed phrase 'advanced sclerosis', replaces the second part of the word skleroza, 'sclerosis', which can be seen as embarrassing or awkward for the sender. This instance of silence is an example of withheld language caused by unwillingness to provide information clearly and openly. Instead, the word is to be understood from the context. Silence performing the function of withheld language appears also when language to be used in its written-out form is socially unacceptable or offensive:

(4) I cant do wends babe what about fri wher $r$ im so upset aswel thay made [name] go \& wile I was away I miss him but I have spook 2 him im back 2 [name2] and $\boldsymbol{f p}$ [fat paki] 
(5) A wiesz chyba tak zrobie $w$ formie testu bo jak znam zycie to powie ze juz tam zaplacila i nie ma i powiem wtedy sss

[You know I might actually do it as a form of test because as far as I can guess she will say that she already paid there and she doesn't have any and then I'll sayfff]

The abbreviation 'fp' ('fat paki') is employed by the sender of the English example (4) to replace the nickname the sender and the recipient use for a third person they both know. Taking into account the offensive character of the nickname, the sender chooses not to use the whole phrase, assuming that the recipient understands its full meaning. Thus, the abbreviation constitutes an instance of in-group language.

The meaning of 'sss', 'fff', in the Polish example (5) and its function as a swearword ('spierdalaj', meaning 'fuck off') can be inferred on the basis of the mutual understanding between interactants based on a certain level of mental intimacy. In text-messages in the Polish sample, silence plays a great role in indicating intimacy existing between participants to the exchange. In text-messages where silence adds to the feeling of intimacy, the sender assumes that the recipient is able to re-construct the intended meaning from the situational context of the exchange.

Instead of conveying silence by means of punctuation, the author of example (6) decides to use a four-word noun phrase, 'Chwila przerwy i zadumy' ('A moment for a break and reverie'). The whole message is surprisingly long - the sender overcomes the constraints of the medium by sending a text more than twice as long as the intended length of texts, i.e., 160 characters. Around half of the message's content is devoted to the description of music that the sender is listening to and, consisting of 23 characters, the solemn moment of silence that $\mathrm{s} / \mathrm{he}$ wants to share with the recipient:

(6) Moi!! I co - Twoj Brat kupuje te beemwice;))? [...] z moich glosNIKow plynie wlasnie Bella! O, poprawka - Belle Francaise;)) O... Patrick. Chwila przerwy i zadumy;)) $C D N$

[Moi!! So - is Your Brother getting that BMW;))? [...] there is Bella floating from my speakers! Oh, actually - Belle Francaise;)) Oh... Patrick. A moment for a break and reverie;)) $T B C]$

This atypical way of signalling silence in text-messages was only found in the Polish sample. It is significant due to the fact that, by expressing silence in this way, the sender expands this already very long message by including this verbal representation of silence, a type of content not normally represented, and not expected, in writing.

English senders limit themselves to the use of ellipsis and represent silence in texts mainly to mark their loss for words, as in example (1), uncertainty of the recipient's response, or to prompt the recipient's reaction. Processing silence can be found in English messages in which the sender wants to show that the content of a message is difficult to express (which can also be seen in the Polish example (1)), e.g.:

(7) My dad's been a bit ill this morning babe, I won't be able to make it, I'm sorry... 
In example (7) the sender apologizes for not being able to show up and marks his/her remorse. The silence at the end of the message serves to strengthen the apology.

This section showed that silence markers occur in both analysed samples. Among the ways of expressing silence textually, there are ellipses and dashes (examples have not been included due to their scarcity in the sample). Polish texters, additionally, tend to express silence verbally and English senders, through the use of large spaces within messages. The range of functions that silence plays in text-messages also varies between the two analysed samples. While both groups of texters employ silence to express their loss for words, replace socially unacceptable terms, or signal that they await for the recipient's reaction or answer, Polish texters also replace parts of embarrassing words with silence and employ it to mark solemn moments that they want to share with the recipient. All in all, Polish senders tend to devote more attention to expressing silence in text-messages than English texters.

\begin{tabular}{|l|l|l|}
\cline { 2 - 3 } \multicolumn{1}{c|}{} & \begin{tabular}{l} 
ENGLISH \\
\multicolumn{1}{c|}{} \\
\cline { 2 - 2 } \multicolumn{1}{c|}{ MESSAGES }
\end{tabular} & $\begin{array}{l}\text { POLISH } \\
\text { MESSAGES }\end{array}$ \\
\hline SILENCES & 78 in 64 messages & 287 in 212 messages \\
\hline - instances per message & 1.22 & 1.35 \\
\hline - percentage of sample & $15.57 \%$ & $28.23 \%$ \\
\hline FILLERS & 24 in 23 messages & 66 in 63 messages \\
\hline - instances per message & 1.04 & 1.05 \\
\hline - percentage of sample & $5.60 \%$ & $8.39 \%$ \\
\hline PHONETICONS & 6 in 6 messages & 42 in 33 messages \\
\hline - instances per message & 1.00 & 1.27 \\
\hline - percentage of sample & $1.46 \%$ & $4.39 \%$ \\
\hline
\end{tabular}

Table 1. The distribution of silences, fillers and phoneticons in the sample.

In face-to-face communication, unintended pauses occur when speakers take more time to formulate their messages. In those situations, in order to keep the floor, they fill in the pauses with prosodic units, such as 'hmm', 'um', etc. Using them allows speakers to claim or keep the floor while processing and formulating the message. Even though texting, as an asynchronous form of communication, does not require claiming the floor, as it constitutes one-way communication (Cherny, 1999) (i.e., messages are constructed and sent as complete units), texters nonetheless employ fillers as a silence-replacing strategy in this written modality. The analysis of the use of fillers in text-messages will be presented in the following section.

\subsection{Fillers}

Own Communication Management (OCM) markers in the form of fillers are characteristic of oral communication, where they help organize utterances, express attitudes to the ongoing situation or message conveyed, and manage the floor in communication. They can be used to mark wondering, or hesitation, as to how to put 
certain thoughts and points in a message. Fillers often precede reformulations; they can also be treated as a signal of processing the message or that the turn is not over yet and that time is needed to formulate subsequent sentences. The use of fillers in English and Polish text-messages, their form and function, will be analysed and presented in this subsection.

The present analysis of fillers will take into account instances of non-language units, such as 'hmm', 'yyy', etc., and their variations, which do not carry propositional meaning. Due to their character, fillers are prone to changes in the length of their final sound. The differences can be treated as cultural or idiosyncratic, as well as resulting from the degrees of emotions expressed. The shortest do not multiply the final sound at all, e.g.:

(8) Lol, $u$ 1st did u miss and um no um ok maybe a little :-)

(9) $\boldsymbol{U}$,skonczylam tlumaczenie, moge je wyslac we wtorek,jak wreszcie wyjde $z$ domu do netu! (przy okazji zdobede szlify z biblioteki). Pozdrawiam

[Uf,I've finished the translation, I can send it on Tuesday when I finally leave the house to use the net! (at the same time I'll arrange the finishing touch from the library). Regards]

In example (8) the sender employs the filler $u m$ twice to signal self-corrections, which can be related to difficulty in formulating an answer to a question. In this case, the sender uses fillers to mark the fact that s/he does not have an answer to the question ready and is still processing the message. As noted earlier, texters have the possibility to process, formulate, and edit their messages before sending them. Therefore, markers of uncertainty occurring in text-messages are always intentional. The filler in the Polish example (9) fulfils a different function, namely it serves to express the sender's relief after finishing the task $\mathrm{s} /$ he was performing. This instance cannot be analysed as a filled pause; it is a filler expressing the sender's attitude.

The above examples include instances of short fillers. Longer fillers indicate a higher level of emotions, especially if they are accompanied by after-silences which emphasize emotions expressed by the preceding filler and are aimed at prolonging them. In the case of Polish text-messages, it is mostly negative emotions that are prolonged, as in example (11). In English examples, prolonged fillers include positive feelings, e.g., of delight, as in example (10). Examples of prolonged markers of uncertainty or hesitation, e.g., ' $\mathrm{hmm}$ ', 'yyy', etc., can be found in both samples.

(10) Mmmm, ninety minutes of joy. Thank you. I like what I hear babe $x x$ (11) eеe... pada:(((

[eee... it's raining: $(()$

Polish senders employ prolonged fillers in almost all cases, e.g., 'yyy', 'hmmm', or 'eee', while English texters often restrict themselves to short ones, e.g., 'hm', 'um', or ' $\mathrm{mm}$ '.

'Hmm' (including its various lengths) is by far the most common filler in both samples. It is common for silences to occur after 'Hmm', which indicates a processing pause before formulating the rest of the message. 'Hmm' can also be 
employed at the end of a speech unit and followed by a question mark. In this function, it serves as a silent question combined with offering help (example (13)), or prompting the recipient's answer or reaction (example (12)). Here, it replaces the hypothetical silence which could precede the response.

(12) 2-2. And ofcourse I will miss $u$;-( and im always honest! Ridles? Hmm? And $u$ ? B honest! I can handle it.

(13) Moi!! Dostalyscie z Efcia przesylke;)) Mam tylko nadzieje, ze sie Efcia za bardzo nie zdziwi ujrzazwszy nadawce... Pomoc Ci szukac slowek do prospektu? Hmmm?

[Moi!! You and Efcia got a package;)) I'm just hoping that Efcia will not be too surprised having seen who the sender is... Do you need any help in collecting vocabulary for the prospectus? Hmmm?]

As seen in the above examples, fillers can occur in any part of the message. However, they most commonly signal that the sender is getting ready to formulate an utterance. This usage is very similar to that characteristic of oral communication, where a speaker employs a filler to claim the floor and delivers an utterance afterwards. In texting, this strategy is not necessary, as the speaker does not need to claim the floor in order to construct a message. The initial ' $\mathrm{hmm}$ ' can also serve to show that the sender processes the message or that thought has to be given to the formulated reply:

(14) Hmm fair enough, I c ure point. So then maybe I shouldnt call u $2 c$ weather or not $u$ miss not talking or txting? Just a thought. So have you fin yet?

(15) Yyy ...Za beznic;)!

[Yyy...For beznic;)!]

Example (15) includes a word inexistent in the Polish language, 'beznic' (bez 'without' + nic 'nothing'), which constitutes an instance of in-group language and signals raising one's glass in a toast.

In this section, I presented an analysis of the use of fillers, i.e., prosodic units replacing unnecessary pauses in conversation, in Polish and English text-messages. I showed that this type of OCM marker is present in both analysed samples. I concluded that there are a number of functions that fillers fulfil in texting. They are used to mark self-corrections, express attitude to the message or the whole interaction, express positive and negative emotions, prompt the recipient's reply or reaction, as well as to process and formulate an utterance. Fillers are prone to variation in the length of their final sound, expressed in writing by means of multiplied letters. This variation can be related to the strength of emotions expressed by the sender. Generally, fillers in the Polish sample are more likely to be longer; however, differences in this matter may be strictly idiosyncratic.

\subsection{Phoneticons}

'Phoneticons' are the only naturally textual type of aural content in text-messages. They can be defined as graphemic representations of voice qualities and sound 
imitations in writing (Knaś, 2006) and their use is characteristic of computermediated communication. They constitute written equivalents of paralinguistic signals and are usually expressed by means of non-standard spelling, multiplied vowels, or by the use of capital letters for emphasis or to represent loud or angry voice, e.g. ' $M Y$ ', 'chooory' ('siiick'). In some cases, clear interpretation of a particular phoneticon cannot be provided, or conclusions in this respect can be drawn only in relation to the context. However, with the popularization of $\mathrm{CMC}$, users globally adopt certain ways of expressing paralinguistic information, e.g., laughter or angry voice. These generally accepted ways are transferred from one mode of computer-mediated communication to another. As noted above, there has been no systematic analysis of aural content in text-messages. There appears only brief mention of its particular types in some of the literature (e.g., Hård af Segerstad, 2005).

While communicating, senders seem to ascribe considerable importance to the tone of voice and the way of speaking, which is visible in the techniques they employ in their text-messages. There are two main ways of presenting voice qualities graphically in text-messages: the employment of capital letters in the middle of a text and the multiplying of letters, which is to be read as indicating prolonged sound in speech. First of all, typing words in the middle of a sentence in capital letters is aimed at giving them additional emphasis. The meaning of such emphasis, which in speech would probably be expressed by a raised, or louder, voice, can be inferred from the content of the message or from the situational context. Nevertheless, one could justifiably state that the most common instances include emphasis resulting from the willingness to stress a particular part of a message, e.g.:

(16) Im playing with MY new phone ;)

(17) Tak wlasnie jest jak Ci nie powiedza ktoredy DOKLADNIE jedzie autobus, nie uscisla ze nie jedzie DOKLADNIE do dworca,a ja nie znam w koncu DOKLADNIE [city]:)))

[That's how it is if they don't tell you which way the bus EXACTLY takes, if they don't specify that it doesn't go EXACTLY to the station, and after all I don't EXACTLY know [city]:)))]

Taking into account spelling, one could say that in speech the capitalized words ('MY' or 'DOKLADNIE') would be uttered with distinctive intonation, probably in a louder, stronger voice. Because this operation is not possible in texting, the sender manipulates textual resources available to him/her and expresses the intended emphasis by means of capital letters, depicting its particular intonation pattern in comparison with the rest of the sentence and adding to the importance of these words in the message.

Another type of phoneticon includes representations of sounds accompanying actions. The most common are: laughter ('hahaha', 'hehe', 'lol', 'es es es', 'hihi'), kisses ('mwah', 'cmok'), clearing one's throat ('ekhm'), and sighing ('heh'). Other examples include purring and swallowing:

(18) I will. Grrrr on your neckx

(19) Cheers!!! gulp:) 
Some of the ways that sounds are depicted in writing are already well-established, but in other cases the sender tries to imitate the intended sound in the best possible way using the available text-tools, e.g., the sound of swallowing gulp depicted in the Polish example (19), and purring 'grrrr' in the English example (18). In these examples, phoneticons can only be interpreted based on the knowledge of the context, which the senders provide in the message. Without the context, 'grrrr' could be interpreted as growling and 'gulp' might not be altogether understandable. Sounds representing actions can also be prolonged, like fillers, by means of multiplying letters.

It is not only the emphasis of particular words that can be expressed by means of phoneticons. In some cases, the speaker imitates the way of speaking that would be characteristic of complaining, moaning, being drunk, or childish, etc. In both examples below, the sender represents in writing the way of speaking they want to imitate. In example (20), the sender expresses remorse and apologizes for offending the recipient. The phrase 'Im sorwwy' is represented as pronounced in a cute and apologetic, possibly childish, way, which is further underlined by the explanation that the sender is making a 'cute face'.

(20) Im sorwwy (cute face) how did I offend \& how can I make up?

(21) Bosh...wszyscy maja do mnie ostatnio pretensje, ze sie nie odzywam. A ja niczym srednio inteligentna blondynka rozkladam rece: "allle o sssooo chozzzi?"

[Gosh...everyone complains to me that I'm not keeping in touch. And

I, like a blonde of average intelligence, spread my arms: "whaaat seems to be the problmm?"]

On the other hand, spelling similar to the one used in example (21) is indicative of the unclear voice of someone who is either drunk or, as suggested explicitly in the text, lacks the mental capacity to understand the situation in which $\mathrm{s} / \mathrm{he}$ is placed. In both cases, the senders devote additional effort to express in writing their emotional attitude or feelings.

Using phoneticons, senders imitate real-life face-to-face exchanges in an even more direct way than through the use of fillers. They show great awareness of the importance of auditory information available in speech and make an attempt to transfer this knowledge, using their skill in manipulating technological resources, to represent paralinguistic information in writing.

The pattern of phoneticons' use in English and Polish samples is very similar. Both groups of senders use all of the described strategies: signalling the tone of voice through the use of capitalized or multiplied letters, depicting sounds accompanying actions, as well as imitating pronunciation characteristic of certain traits or states of mind. In certain cases, this strategy is also used to mark pronunciation characteristic of certain ethnic groups (possibly marking their in-group identity); this usage is strictly limited to the English sample.

\section{Implications for system development}


The analysis has shown that sounds and silence are often employed in text-messages. The fact that senders turn to textual representations of sounds and silence in their messages can be seen as an indication of the fact that this type of content plays a significant role in texting. Choosing to convey auditory information in their messages, senders signal its virtual presence in this visual-only (textual) form of communication.

With the tendency to make use of automated communicative media and the introduction of more advanced elements into mobile communication, one can wonder whether the possibility of automating the occurrences of silence and sound in textmessages exists. Bearing in mind the text-only character of the medium involved and the auditory character of the content accounted for in this article, there are two possible scenarios for software developers. Firstly, sound and silence in texts can be represented visually through font types and icons. However, in this case, one type of visual information would be replaced by another. Aural information still remains within the sphere of the visual. Another option involves introducing audible cues into texting. Doing this means that the form and character of text-messages would approach MMS-messages, in which sound files and images can be attached to a message and transferred from one mobile phone to another. Also, one needs to bear in mind the discreet character of texting, which is often used in environments where communication by voice is not possible or not allowed. Introducing audible content to text-messages undermines the silent character of this form of communication.

All in all, more vivid representation of sound and silence in text-messages would certainly add to the enjoyment related to the use of this means of communication, but, at the same time, one can see it discouraging users from developing new ways of representing face-to-face communication textually.

\section{Conclusions}

In this paper, I presented an analysis of representations of sound and silence in textmessages sent by English and Polish texters. Aural information accompanies face-toface communication and is not expected to occur in text-only forms of computermediated communication. Through the comparative analysis of the two samples, I established that aural cues are not only present in texting, but that they constitute an important part of this necessarily constrained form of communication. I divided representations of sound and silence into three categories based on their form: silences, fillers, and phoneticons. I concluded that all of these types of content can be found in both of the analysed samples. However, there are some differences in their usage between the Polish and English groups, signalling possible cultural variation.

Silence can be textually represented by means of punctuation, verbal descriptions, or gaps within a message. Polish texters employed silence markers in a larger variety of functions and showed more innovativeness in expressing silence in writing than the British.

Fillers were shown to mark self-corrections, express the sender's attitudes and emotions, and serve as communication management devices. The main difference in the use of fillers between the two samples was in their form, with the Polish senders showing a tendency to employ longer fillers than the English senders. 
Phoneticons, as the only 'indigenous' text-based form of auditory information found in texts, were equally popular in the two samples. Both groups shared the usage of phoneticons to mark a louder voice or atypical pronunciation. Both groups also represented sounds accompanying communication and paralinguistic cues in writing.

Based on the analysis, I concluded that senders show great awareness and skill in imitating aural information textually. In doing this, they employ text-tools available in texting in a creative way, constructing their messages to convey information normally only available in face-to-face communication.

Finally, I discussed the possible ways of representing silence and sound in texts and the consequences of making this process automated. I pointed to the issues that may prove important in considering the development of mobile phone software in the light of the character of the modality involved, as well as the sender's personal approach to texting.

\section{References}

Allwood, J. (2000) An Activity Based Approach to Pragmatics. In: Bunt, H. \& Black, B. eds. Abduction, Belief and Context in Dialogue: Studies in Computational Pragmatics. Amsterdam: John Benjamins, pp. 47-80.

Cherny, L. (1999) Conversation and Community: Chat in a Virtual World. Stanford: CSLI Publications.

Culnan, M.J. \& Markus, M. L. (1987) Information Technologies. In: Jablin, F.M. Putnam, L.L. Roberts, K.H. \& Porter, L.W. eds. Handbook of Organizational Communication: an Interdisciplinary Perspective. Newbury Park; Sage, pp. 420-443.

Dauenhauer, B.P. (1973) On Silence. Research in Phenomenology, 3(1), pp. 9-27.

del-Teso-Craviotto, M. (2004) Virtually There: Creating Physicality in Dating Chat Rooms. Texas Linguistic Forum, 48, pp. 73-82.

del-Teso-Craviotto, M. (2006) Language and Sexuality in Spanish and English Dating Chats. Journal of Sociolinguistics, 10 (4), pp. 460-480.

Goffman, E. (1978) Response Cries. Language, 54(4), pp. 787-815.

Hård af Segerstad, Y. (2002) Use and Adaptation of Written Language to the Conditions of Computer-Mediated Communication. Göteborg: Göteborg University.

Hård af Segerstad, Y. (2005) Language in SMS - a Socio-Linguistic View. In: Harper, R. Palen, L. \& Taylor, A. eds. The Inside Text: Social, Cultural and Design Perspectives on SMS. Dordrecht: Kluwer Academic Publishers, pp. 33-51.

Handke, K. (2002) Milczymy mówiąc. In: Handke, K. ed. Semantyka milczenia. Vol. 2. Warszawa: Slawistyczny Ośrodek Wydawniczy, pp. 217-222. 
Herring, S. (2001) Computer-mediated Discourse. In: Schiffrin, D. Tannen, D. \& Hamilton, H.E. eds. The Handbook of Discourse Analysis. Oxford: Blackwell, pp. 612-634.

Jaworski, A. (1993) The Power of Silence: Social and Pragmatic Perspectives. Newbury Park: Sage.

Jaworski, A. (2000) Silence and small talk. In: Coupland, J. ed. Small talk. Harlow: Longman, pp. 110-132.

Knaś, A. (2006) Bonding Content and Limited Space: The Analysis of Text-messages (SMS) Written by British, Polish and Finnish Native Speakers. unpublished Master's thesis, Warsaw University.

Kurc, B. (2003) Opowiadanie Obrazem. Łódź: Piątek Trzynastego.

Laver, J. (1981) Linguistic routines and politeness in greeting and parting. In: Coulmas, F. ed. Conversational Routine. The Hague: Mouton, pp. 289-304.

Ling, R. (2004) Just connect: The social world of the mobile phone. Psychology Review, 11, pp. 10-13.

Malinowski, B. (1923) The problem of meaning in primitive languages. In: Ogden, C.K. \& Richards, I.A. eds. The meaning of meaning. London: Routledge \& Kegan Paul, pp. 296-336.

Maschler, Y. (1998) Rotzè lishmoa kéta? 'wanna hear something weird/funny [lit. 'a segment']?': The Discourse Markers Segmenting Israeli Hebrew Talk-ininteraction. In: Jucker, A.H. \& Ziv, Y. eds. Discourse markers: description and theory. Amsterdam: John Benjamins Publishing Company, pp. 13-60.

Miller, W. (1993) Silence in the Contemporary Soundscape. unpublished Master's Thesis, Simon Fraser University, Dept. of Communications.

Pearsall, J. ed. (1998) The New Oxford Dictionary of English. Oxford: Clarendon Press.

Poyatos, F. (1992) The Audible-Visual Approach to Speech as Basic to Nonverbal Communication Research. In: Poyatos, F. ed. Advances in nonverbal communication. Sociocultural, clinical, esthetic and literary perspectives. Amsterdam: John Benjamins Publishing Company, pp. 41-57.

Rokoszowa, J. (1999) Jezyk - Czas - Milczenie. Kraków: Wydawnictwo Oddziału PAN.

Sajavaara, K. \& Lehtonen, J. (1997) The Silent Finn Revisited. In: Jaworski, A. ed. Silence - Interdisciplinary Perspectives. Berlin/New York: Mouton, pp. 263-283. 
Schmitz, U. (1994) Eloquent silence. Available from: http://www.linse.unidue.de/linse/publikationen/silence.html [accessed 14 September 2008].

Tannen, D. (2002) To nie tak! Jak styl konwersacyjny ksztattuje relacje z innymi. Poznań: Zysk i S-ka.

Tannen, D. \& Saville-Troike, M. eds. (1985) Perspectives on Silence. Norwood, NJ: Ablex Publishing Corporation.

Thurlow, C. (2003) Generation Txt? The sociolinguistics of young people's textmessaging. Discourse Analysis Online.

Available from: http://extra.shu.ac.uk/daol/index.html [accessed 14 September 2008].

Yngve, V. (1970) On Getting a Word in Edgewise. In: Papers from the Sixth Regional Meeting of the Chicago Linguistic Society. Chicago: Chicago Linguistics Society, pp. 567-577.

Żydek-Bednarczuk, U. (1994) Struktura tekstu rozmowy potocznej. Katowice: WUŚ. 